veröffentlicht in: Antes, R., Hansjürgens, B., Letmathe, P. (Hrsg.) (2008) Emissions Trading - Institutional Design, Decision Making and Corporate Strategies, New York: Springer, 183-192.

\title{
Links of Corporate Energy Management Strategies in Europe with the European Union Emissions Trading System and Environmental Management Systems
}

\author{
Marcus Wagner
}

Bureau d'Economie Théorique et Appliquée, Université Louis Pasteur, 61 avenue de la Fôret Noire, 67085 Strasbourg (E-mail: wagner@cournot.u-strasbg.fr, Tel. : +33 390242 099, Fax: +33 390242 071) and Dr. Theo Schöller-Stiftungslehrstuhl für Technologie- und Innovationsmanagement, TU München, Arcisstr. 21, 80333 München, (E-mail: wagner@wi.tum.de, Tel.: +49 89289257 47, Fax: +49 89289 $25742)$

\begin{abstract}
This chapter analyses the interaction of the novel emissions trading directive of the European Union with energy management strategies of European firms and the empirical determinants of corporate energy management activities related to these. After a brief introduction, three generic corporate energy management strategies to address climate change are introduced and discussed. This also takes into account the embeddedness of energy management in environmental management systems, which may lead to a policy interaction with the emissions trading directive. The determinants of specific energy management activities linked to the different corporate energy management strategies are subsequently analysed empirically. It is found that especially implementation of environmental management systems has a very positive effect on activities. The paper concludes by discussing the implications of this for the European Union's emissions trading directive and the interaction of the different empirical determinants for activities and strategies with climate policy initiatives on firms in Europe. In particular, the findings confirm that fostering environmental management systems which achieve emission reductions and the emissions trading directive lead to interaction that increases the allocative efficiency of a system using both environmental policy instruments over one which only uses one of them, i.e. that favourable policy interaction is possible.
\end{abstract}

JEL classification: L19, Q01, Q48

Keywords: climate policy, emissions trading, energy management, environmental management systems, European Union

Appeared in:

Wagner, M. (2008). Links of corporate energy management strategies in Europe with the European Union emissions trading system and environmental management systems (pp. 183-192). In: Antes, R., Hansjürgen, B. \& Letmathe R. (Eds.) (2008), Emissions Trading. Institutional Design, Decision Making and Corporate Strategies. Springer. 


\section{Introduction}

Due to its large emission levels and a long lifetime in the atmosphere, carbon dioxide still contributes most to the greenhouse effect. The main source of global greenhouse gas (GHG) emissions, and in particular carbon dioxide emissions is the combustion of fossil fuels to generate energy. Currently international co-operation to influence and stabilise global climate change is still on its way to being fully institutionalised within the Framework Convention for Climate Change. Whilst the main objective resulting from Conference of Parties (CoP) 7, the ratification of the Kyoto Protocol did seem unlikely for a long time, the change in position of Russia finally brought the Kyoto Protocol in force. ${ }^{1}$ Global emission trading is become increasingly relevant in this context (see e.g. Antes et al. 2006) and is to become a major element under the Kyoto Protocol from 2008 onwards. The slow progress on the ratification of the Kyoto Protocol had led the European Union (EU) in March 2000 to propose a closed European emission trading (ET) system (EU ETS), also to form the basis for inter-country ET from 2008 onwards (EC 2003). This was detailed in a draft EU directive on GHG emissions trading between firms in October 2001 (EC 2003) which was ratified by the European Parliament in late summer 2003 after the second reading of the directive in the parliament. The system became active at the beginning of 2005 and enables trading between EU firms. This landmark event raises the issue of how emission trading interacts

${ }^{1}$ However, Russian use of its bargaining power resulted in a weakening of the Protocol's targets (Böhringer \& Vogt 2004). 
with corporate energy management strategies and activities of European firms and what the relevant determinants for this are. Any analysis here needs to start with the broader strategic frame for energy management strategies and to take into account their embededness in environmental management systems (EMS), since this implies the possibility of an interaction with the EU ETS. The remainder of the paper is structured as follows: after deriving the different energy management strategies for business responses towards climate change, the paper introduces data and methods and subsequently provides empirical results on the drivers for energy management activities which reflect these strategies. It concludes by analysing the implications of the findings.

\section{Corporate energy management strategies and links to EMS, the EU ETS and climate policy}

There are three strategies for the corporate sector to address climate change by means of energy management whilst at the same time not jeopardizing economic performance. ${ }^{2}$ These are: improvement of energy efficiency (e.g. through adoption of measures or activities to reduce energy use in production or energy use required for transport, whilst keeping production output constant), increased use of renewable energies or fuel switching in general (e.g. by means of

\footnotetext{
2 These three strategies are basically input-oriented. Emissions-oriented approaches are defined here as any end-of-pipe measures for the reduction of air pollutant emissions and are not included because they are thought to jeopardize central business objectives. The empirical analysis however includes the reduction of air emissions for completeness. Flexible mechanisms are an input-oriented strategy where reductions in GHG emissions are achieved not directly on site, but indirectly.
} 
measures for substituting non-renewable resources such as fossil fuels) and the use of flexible mechanisms (like Joint Implementation (JI), the Clean Development Mechanism (CDM) or ET). The first of these strategies, improvement of energy efficiency, has been on the corporate agenda for quite some time, initially triggered by the 1970s oil crises and recently predominantly because of increasing energy taxes and oil prices. Unfortunately two factors limit the scope of this strategy. Firstly, because of its considerable history, energy efficiency improvements through direct measures (such as e.g. process integration, combined heat and power, heat and steam recovery) at plants or sites have often reached a level that leaves limited scope for cost-efficient improvement, since frequently the process-related limits are very close. Secondly, market imperfections such as lack of information hinder even cost-efficient investments in energy efficiency (Jaffe and Stavins 1994; Sanstad and Howarth 1994). Hence the potential for energy management-based GHG reductions by means of increased energy efficiency seems to be most viable in countries with low efficiency levels in energy generation and utilisation such as India, the U.S. and the post-socialist economies of Central and Eastern Europe or China rather than in the EU. Despite of this, new technologies bear some additional potential in the EU as well. For example, the specific energy consumption of thermal processes is expected to decrease by $30 \%$ due to novel membrane technology to replace thermal processes. Especially in the consumer market segment of the electricity industry considerable potential also exists for demand-side based energy management strategies such as 
Demand Side Management or Least-Cost Planning which were also found to be attractive to energy suppliers in financial terms (Greening 1995). For the second strategy mentioned, namely the increased use of renewable energy technologies and sources, or more generally for fuel switching, the longer-term potential is high, since it leads to direct GHG emission reductions. Particular potential here exists in countries with a fossil-fuel intensive energy mix and for renewable energy technologies, one example of which with significant potential are photovoltaics (PV). For companies in the EU corporate sector, PV will however only be a viable energy or fuel source (and thus an element of their corporate energy management strategies), if they can compete on price with fossil fuel-based technologies. This would require prices to fall from currently around $3-4 \$ / \mathrm{Wp}$ to around $1.5 \$ / \mathrm{Wp}$ by 2010 , which can only be achieved by means of significant innovation efforts not only of solar cell and PV module technology but also associated manufacturing processes. As a note of caution and a remainder that such radical innovation is not a 'free lunch', Grubb (1997) points to the relevance of early (government supported) PV innovation activities and associated induced innovation benefits which may require more systematic market support in order for PV technologies to become a competitive energy source in the increasingly liberalized and deregulated EU energy markets. Finally, a third general strategy for corporate energy management consistent with firm's economic objectives to address climate changeinduced demands is the use of flexible mechanisms like JI, CDM and ET which are the mechanisms of the Kyoto Protocol, but which 
can also be used outside of a protocol, as long as regulated (as e.g. in the EU ETS). Whilst CDM and JI enable European industry to exploit marginal abatement cost differences between countries, incentives for early action are currently comparatively low. ${ }^{3}$ Whilst the first two strategies together with end-of-pipe reductions of air emissions lead to lower GHG emissions and therefore for lower demand for certificates under e.g. the EU ETS, the third strategy of flexible mechanisms creates offsetting credits which may reduce further certificate demand because they may be counted towards the emissions remaining after use of the other two strategies introduced above plus use end-of-pipe emissions reductions.Corporate energy management strategies are frequently embedded in EMS and this may actually lead to favourable policy interactions between them and the EU ETS in case that EMS implementation would have a positive effect on strategy adoption. The drivers of energy management strategies can empirically be analysed in terms of determinants for corporate energy management activities. This is possible, because of the largely one-to-one linkage of the different energy management activities to be analysed to only one of the generic strategies. The activities included in the empirical analysis are the reduction of energy use in

\footnotetext{
${ }^{3}$ There is for example uncertainty regarding the use of emission reduction units or emission credits from JI/CDM in the EU emissions trading system with the current status being that such use would be possible from 2008 onwards in the scope of the Kyoto Protocol. Hence, whilst early JI/CDM projects may have positive reputation effects for firms, they run the risk of gaining only limited economic benefits. It seems that this would merit a cautious approach by firms towards integrating flexible mechanisms into their existing energy management strategies. For example, if firms carried out energy management activities in the context of an existing EMS, then they would continue to implement all cost effective activities as before (see also Hamschmidt \& Dyllick (2002) on an evaluation of EMS with regards to profitability and an analysis of links to learning processes).
} 
production (EUSE) and the reduction of energy use in transport (ENTR) which are directly linked to the first generic strategy of increasing energy efficiency. The substitution of non-renewable resources such as renewable energy for fossil fuels (RENS) is a direct proxy for the second generic strategy of fuel substitution whilst the reduction of emission through air pollutants (EMAR) is closely linked to emissions-oriented end-of-pipe approaches. Whilst the activities do not directly correspond to the three generic strategies introduced earlier, there are very close links. Thus by analyzing the drivers for above energy management activities, determinants of higher or lower GHG emissions, and ceteris paribus higher or lower certificate demand can be identified. Application of flexible mechanisms by a firm can then further reduce certificate demand. Unfortunately, at the time of the last EBEB survey, the EU ETS was not in force and empirical data on its effects in firms were not available. However, this is not considered a limitation since Kyoto and the EU ETS came only in force in 2005, it seems unlikely, that firms would already use flexible mechanisms as a strategy to a larger degree. In addition to this, it would seem that firms would change their energy management activities and strategies fundamentally because of Kyoto or the EU ETS. It rather seems that firms would do so gradually due to existing resource allocations and because flexible mechanisms will always only be a subset of energy management strategies and activities. Therefore, the dependent variables proposed earlier for an empirical analysis are the most important drivers for the level 
of GHG emissions by firms and thus the number of emission certificates required which also allows linking them to emissions trading.

\section{Data and research method}

The empirical analysis for which results are presented in the following section is based on data collected during the European Business Environment Barometer (EBEB) survey. This is a (roughly) biannual survey on the state of environmental management in practice carried out in several European countries based on a mail questionnaire. The questionnaire asks firms about their main environmental effects and stakeholder demands; the main management and technological activities carried out, as well as for an evaluation of their degree of sophistication, and the extent of their corporate environmental strategy. ${ }^{4}$ The results reported in the following are based on the last EBEB survey round in 2001 carried out in nine countries (Belgium, France, Germany, Hungary, Netherlands, Norway, Sweden, Switzerland, United Kingdom). Prior work provides descriptive results and some comparison between countries (Baumast \& Dyllick 2001). In the 2001 EBEB round, almost 2100 firms in manufacturing industries replied surveyed Europe-wide. For Germany, after having sent the first questionnaires to about 2000 companies, 334 usable questionnaires in total were returned, corresponding to an effective response rate of 16.7 percent. This response rate is in consistent with the average response rate of other countries (e.g. Hunga-

\footnotetext{
${ }^{4}$ The full questionnaire can be accessed in English at www.agf.org.uk/pubs/pdfs/UK.pdf
} 
ry $35.2 \%$, Switzerland $14.9 \%$, Sweden $36.3 \%$, Netherlands $18.1 \%$ and United Kingdom 10.7\%) for which data was collected during the 2001 EBEB survey round (Baumast \& Dyllick 2001). Amongst the technical activities of environmental management surveyed in the EBEB questionnaire were four relating to energy management. For each of these (detailed at the end of Section 2 above), respondents had to state whether their firm carried out the measure or not. Given this binary dependent variable, a binary Logit model (Greene, 2000). Since 30 independent variables were used in the regression analysis, data for all countries was pooled. The model was estimated using Maximum Likelihood (ML).

The embededness of energy management strategies and activities into EMS suggests to include the latter as a determinant since likely EMS implementation has a positive effect on the adoption of strategies/activities. This would result in reduced emission levels and lower likelihood of ETS participation. Even though the levels of EMS implementation ("Not implemented", "Considering", "In process", "Implemented") could be seen as an ordinal variable, this would assume that there are equal changes of effect between levels.

To avoid this (restrictive) assumption, dummy variables were introduced (with no EMS existing as the reference group) instead, to take into account the possibility of different changes between two adjacent levels. ${ }^{5}$ Firm size was measured by the number of employees (in thousands), and country membership through dummy variables for each country with firm location in the Netherlands being the

\footnotetext{
${ }^{5}$ The results of the estimation confirm that this cautionary approach was appropriate.
} 
reference group omitted in the regression. Sector membership was also measured through dummy variables based on two-digit NACE codes with firms in the metal products sector being the reference group. Other control variables included were the logarithm of firm age in years, market growth (measured on a 5-point scale to assess if the main market of a firm has increased or decreased over the last three years), firm legal status (in terms of a dummy variable taking unity value if the firm is solely owned) and overall profitability (measured on a 5-point scale to assess if a firm is profit- or lossmaking). Based on these considerations, the Logit model for the analysis to follow is defined as:

odd of activity $i=$ function (firm size, sector dummies, country dummies, market growth, firm age, legal form, overall profit, level of EMS implementation).

\section{Estimation results}

Table 1 provides the results of the estimation a well as several important statistics providing information about the quality of the estimation. These are the Likelihood Ratio (LR) test, Nagelkerke's R ${ }^{2}$ and the Cox \& Snell $\mathrm{R}^{2}$ all of which provide some assessment of the overall quality of the model. In addition, the Hosmer-LemeshowTest provides an indication about the goodness-of-fit of the model.

The most important finding is that the strongest significant effect, positive across all variables, is that of environmental management system (EMS) implementation. Also, the strength of this effect is in- 
creasing across different implementation stages and is strongest for firms which have a fully implemented EMS: here the effect was significant, positive and economically relevant for all four dependent variables/energy management activities (proxying for strategies) analysed. Also for the variable of EMS implementation in progress significant positive effects were found in the case of activities to reduce energy use in production and for the substitution of nonrenewable resources. The positive effect of an incomplete EMS can potentially be explained by the fact that this implies that at least some elements of an EMS already exist. This (and even more so full implementation) enables more systematic identification of attractive activities based on learning processes and better information quality.

Next to EMS, important findings are that for energy use in production (EUSE), all country dummies except for Belgium (which is also a Benelux state) have a significant and strong negative effect relative to the Netherlands as reference groups. This is less the case for the other energy-related dependent variables (where for only few countries the negative effect relative to the Netherlands is negative) and is even turning to largely positive for energy use in transport (ENTR). These observations may be explained by the leading role the Netherlands have in industrial energy efficiency. Apart from these findings, the country effect is generally very negative for France and to a little lesser degree for Norway.

As well, a number of sectoral dummy variables are significant relative to the dummy group. Again the effect seems to be variable-dependent: exclusively positive for fuel substitution (RENS) and 
transport energy use, and more neutral for energy use in production and the reduction of air emissions (always relative to metal products).

Table 1: Results of Logit models for different dependent variables

\begin{tabular}{|c|c|c|c|c|}
\hline $\begin{array}{l}\text { Dependent variable } \\
\text { Independent variable }\end{array}$ & $\begin{array}{l}\text { EUSE } \\
\text { Beta }\end{array}$ & $\begin{array}{l}\text { RENS } \\
\text { Beta }\end{array}$ & $\begin{array}{c}\text { EMAR } \\
\text { Beta }\end{array}$ & $\begin{array}{l}\text { ENTR } \\
\text { Beta }\end{array}$ \\
\hline Food & .386 & .090 & -.342 & .933 \\
\hline Textiles & .304 & -.107 & -.798 & .212 \\
\hline Leather & -.115 & .421 & .037 & .583 \\
\hline Wood & .147 & .551 & .836 & .662 \\
\hline Pulp/Paper & -.143 & 1.100 & .059 & .502 \\
\hline Print & -.399 & .199 & .155 & .159 \\
\hline Energy & .857 & -.633 & .021 & -.654 \\
\hline Chemical & -.175 & .510 & -.147 & -.237 \\
\hline Rubber & .796 & .048 & -.143 & .479 \\
\hline Nonferrous & .112 & 1.420 & .759 & .448 \\
\hline Machines & -.365 & .076 & -.168 & .128 \\
\hline Electric & .141 & .341 & -.080 & .040 \\
\hline Transport & -.042 & .567 & -.536 & .606 \\
\hline Other & -.464 & .370 & .126 & .176 \\
\hline Germany & -.591 & -.357 & .160 & .357 \\
\hline Sweden & -.939 & -.142 & -.327 & -.260 \\
\hline Switzerland & -.631 & .210 & .192 & .846 \\
\hline United Kingdom & -.804 & .231 & -.419 & .083 \\
\hline Hungary & -.635 & -.391 & .431 & .910 \\
\hline France & -.911 & -2.377 & -.665 & -.590 \\
\hline Belgium & -.039 & .100 & -.014 & .098 \\
\hline Norway & -.826 & .066 & -.645 & -.357 \\
\hline Market growth & -.093 & .024 & .065 & -.227 \\
\hline $\begin{array}{l}\text { Considering EMS im- } \\
\text { plementation }\end{array}$ & .225 & .428 & .320 & .247 \\
\hline $\begin{array}{l}\text { EMS implementation in } \\
\text { progress }\end{array}$ & .304 & .559 & .258 & .086 \\
\hline EMS implemented & .964 & 1.036 & .686 & .471 \\
\hline Firm legal status & .033 & .082 & -.156 & -.038 \\
\hline Overall profitability & -.078 & -.011 & .001 & .063 \\
\hline Number of employees & .266 & .003 & .080 & .010 \\
\hline Firm age & .046 & .001 & .021 & .004 \\
\hline Constant & 1.018 & -2.081 & -.002 & -.696 \\
\hline Number of observations & 1527 & 1109 & 1324 & 1333 \\
\hline Degrees of Freedom & 30 & 30 & 30 & 30 \\
\hline Hosmer-Lemeshow test & 14.277 & 4.961 & 3.442 & 4.649 \\
\hline
\end{tabular}




\begin{tabular}{ccccc} 
Cox \& Snell R-squared & 0.100 & 0.071 & 0.068 & 0.079 \\
Nagelkerkes R-squared & 0.136 & 0.107 & 0.093 & 0.110 \\
-2 Log-Likelihood & 1857.1 & 1135.7 & 1654.1 & 1574.4 \\
Chi-squared (LR test) & $\mathbf{1 6 0 . 6 0}$ & $\mathbf{8 1 . 6 5}$ & $\mathbf{9 3 . 0 8}$ & $\mathbf{1 0 9 . 2 8}$ \\
\hline
\end{tabular}

Bold and italicised figures mean significance at the $1 \%$ level, bold figures at $5 \%$ level, and italicised figures significance at the $10 \%$ level; leading zeros for all Betas were surpressed.

Next to the identified country, industry, and EMS influences, some firm size effects were positive and significant in the model.

However, these were not economically relevant, due to the small coefficients which have almost no effects on the odd ratios. Effects were only significant for activities to reduce energy consumption in production and for the reduction of air emissions, but not for the other variables. Finally, a strongly growing main market had a significant negative effect on activities to reduce energy use in transport.

This seems plausible, since firms which act in a strongly growing market likely have to expand their transportation activities over-proportionally in order to participate in market growth. This may lead to reduced attention to energy use in transportation, due to a strong managerial focus on achieving the expansion of transport activities.

Wagner (2002) found for the German EBEB sub-sample no significant differences in 2001 ratios of energy consumption per employyee (data for which was not gathered in the other countries) between firms with and without EMS certification, as can be seen in Figure 1.

As well, Figure 1 shows no positive trend from 1991 to 2001, but the sample size is very small. Compared with the Figure 1, the results based on Table 1 indicate that the relevant aspect is likely implementation, not certification, supporting the research design used. 


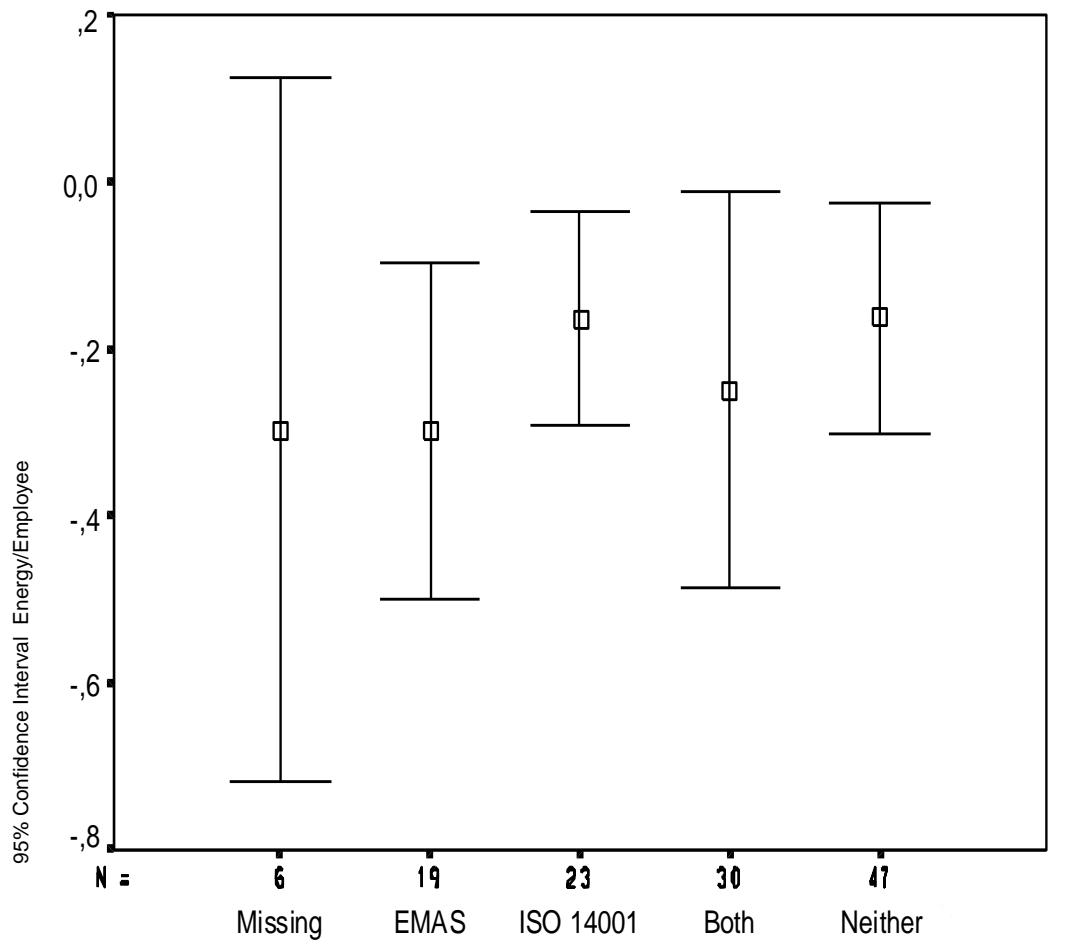

Type of EMS certification

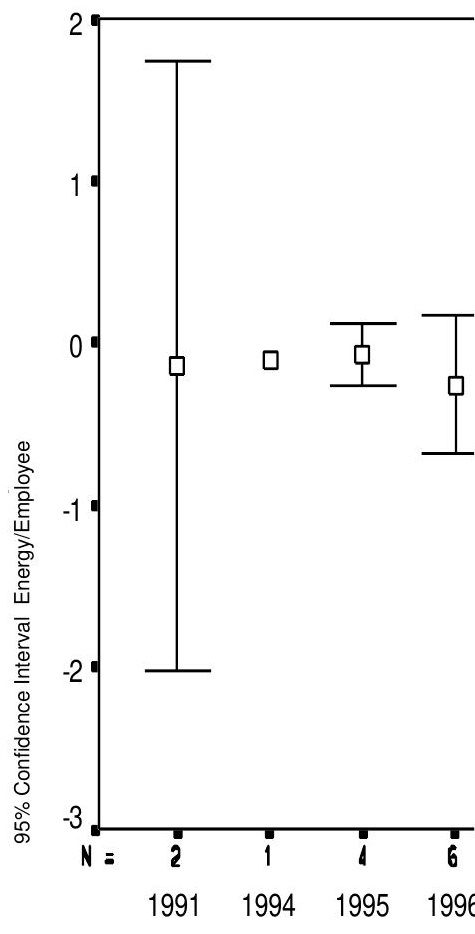

Year of EMS implementation can

be understood as drivers for corporate emission levels as well as proxy measures for different generic strategies. Therefore they are also linked to firms' demand for emission certificates. For example, if firms pursue many energy efficiency improvement or fuel substation activities (and the results of the regression analysis inform us that one main determinant for doing so is EMS implementation), then certificate demand is likely lower, all else being equal. In other words: positive (and significant) effects in Table 1 mean that the 
probability of firms to reduce their energy use is positively affected and thus the demand for certificates will be reduced. Conversely, negative and significant coefficient would imply a lower probability for reducing corporate energy consumption and hence a higher demand for emission certificates. The significant positive effect of EMS implementation on energy management activities ensures that a mechanism links EMS and the EU ETS through the effect on certificate demand which ensures that the equilibrium market price for certificates is equal to the marginal abatement costs from carrying out energy management activities under an EMS: if the marginal cost of energy management activities are above the certificate price, then a firm would choose to carry out the activity. If the cost of the activity is above the certificate price, then the firm would opt to buy certificates. Hence social welfare in a system using both instruments will be higher than in one using only one, either EMS or ETS. The EMS hence plays a critical role here, because it is its implementation that enables the correct identification of marginal costs for the activities, based on learning processes and better information quality.

\section{Acknowledgements}

Valuable comments have been received from two anonymous reviewers as well as the editors of this volume, especially Ralf Antes. Feedback is also acknowledged from the participants of the $2^{\text {nd }}$ Joint Research Workshop "Business and Emissions Trading" in Wittenberg and from Jörn Block of the Schöller Chair in Technology and Innovation Management. 


\section{References}

Antes, R., Hansjürgens, B. and Letmathe, P. (eds.): 2006, Emissions Trading and Business, Physica, Heidelberg/New York.

Baumast. A. \& Dyllick, T. (eds.): 2001, Umweltmanagement-Barometer 2001 (IWÖDiskussionsbeitrag Nr. 93), St. Gallen, IWÖ-HSG, University of St. Gallen.

Böhringer, C. and Vogt, C.: 2004, The dismantling of a breakthrough: the Kyoto Protocol as symbolic policy, European Journal of Political Economy 20(3), 597-617.

EC: 2003, Directive 2003/87/EC of the European Parliament and of the Council of 13 Oct 2003 establishing a Scheme for Greenhouse Gas Emission Allowance Trading within the Community and Amending Council Directive 96/61/EC, Brussels, EC.

Greene, W.H.: 2000, Econometric Analysis, $4^{\text {th }}$ Ed., New Jersey

Greening, D.W.: 1995, 'Conservation Strategies, Firm Performance, and Corporate Reputation in the U.S. Electric Utility Industry', Research in Corporate Social Performance and Policy Supplement 1, 345-368.

Grubb, M.: 1997, 'Technologies, energy systems and the timing of CO2 emission abatement: An overview of economic issues', Energy Policy 25(2), 159-172.

Hamschmidt, J. and Dyllick, T.: 2002, 'ISO 14001: Profitable? Yes! But is it ecoeffective?', Greener Management International 34, 43-54.

Jaffe, A.B. and Stavins, R.N.: 1994, 'Energy-efficiency investments and public policy', The Energy Journal 15(2), 1-23

Sanstad, A.H. and Howarth, R.B.: 1994, "Normal' markets, market imperfections and energy efficiency', Energy Policy 22(10), 811-818.

Wagner, M.: 2002, The Relationship between environmental and economic performance of firms and the influence of ISO 14001 and EMAS, Paper presented at the 5th EMANEurope Conference, University of Gloucestershire, Cheltenham, UK, 11-12 Feb 2002. 